\title{
Within-session changes in responding during concurrent fixed interval variable interval schedules
}

\author{
FRANCES K. MCSWEENEY and SAMANTHA SWINDELL \\ Washington State University, Pullman, Washington \\ and \\ JEFFREY N. WEATHERLY \\ McNeese State University, Lake Charles, Louisiana
}

\begin{abstract}
Rats (Experiment 1) and pigeons (Experiment 2) responded on several concurrent fixed interval variable interval schedules. The programmed rate of reinforcement varied from 15 to 240 reinforcers per hour across conditions for each component. The rate of, but not the time spent, responding on each component usually changed within sessions. The patterns of changes in response rates within the session were similar enough for the two components that the bias and sensitivity to reinforcement parameters of, and the percentage of the variance accounted for by, the generalized matching law did not change within the session. These results imply that within-session changes in responding do not cause problems for assessing the validity of the generalized matching law when subjects respond on concurrent fixed interval variable interval schedules. They may help to explain why the matching law provides a good description of the data.
\end{abstract}

Response rates often change systematically within experimental sessions (see, e.g., McSweeney, 1992). In the present experiments, the implications of these withinsession changes in responding for the generalized matching law (GML), the leading description of concurrentschedule performance (Baum, 1974), were examined. The GML appears in Equation 1. The rates of responding emitted on, the time spent responding on, and the rates of reinforcement obtained from, one component of a concurrent schedule are symbolized by $P_{1}, T_{1}$, and $R_{1}$, respectively. The same variables for the other component are symbolized by $P_{2}, T_{2}$, and $R_{2}$. The $a$ and $b$ parameters are bias and sensitivity to reinforcement, respectively. Bias represents preference for a component that is not explained by differences in the rates of reinforcement provided by the components. Sensitivity represents the degree to which preference changes with changes in the ratio of the rates of reinforcement.

$$
\frac{P_{1}}{P_{2}}=\frac{T_{1}}{T_{2}}=a\left(\frac{R_{1}}{R_{2}}\right)^{b} .
$$

Within-session changes in responding would cause problems for assessing the validity of the GML if those

This material is based on work supported by the National Science Foundation under Grants IBN-9207346 and IBN-9403719. Correspondence concerning this article should be addressed to F. K. McSweeney, Department of Psychology, Washington State University, Pullman, WA 99164-4820 (e-mail: fkmcs@mail.wsu.edu). changes also produced within-session changes in the parameters and fit of the GML. In that case, the parameters and fit of the GML would depend on the time in the session at which they were measured. Because longer sessions would sample different values of the parameters and fit than shorter sessions (McSweeney, 1992; McSweeney, Roll, \& Cannon, 1994), the parameters and fit would also vary with session length, an undesirable result.

Within-session changes in the parameters and fit of the GML might occur if the within-session changes in response rates differed for the two components of a concurrent schedule. Suppose that responding during each component increased to a peak and then decreased within experimental sessions, as responding often does (see, e.g., McSweeney, 1992). Suppose also that the withinsession patterns differed for the two components (e.g., the peak was reached at different times). Then, the ratio of the rates of responding during the two components would change within the session. The fit and parameters of Equation 1 would also change, unless the ratio of the obtained rates of reinforcement varied in the same way as the ratio of response rates. Similar changes in rates of responding and reinforcement are unlikely when the components of concurrent schedules provide interval schedules. Large changes in response rates have little effect on obtained rates of reinforcement for those schedules.

Within-session changes in response rates would cause fewer problems for evaluating the GML if the changes occurred similarly for the two components. Suppose, for example, that within-session changes in responding are produced by changes in a multiplier that modulates the ab- 
solute rates at which subjects respond. If this multiplier changed in the same way within sessions for the two components, its effect would cancel out when ratios of rates of responding were calculated. As a result, the parameters and fit of the GML might be constant within the session.

Within-session changes in responding do not distort the interpretation of the GML when the components of the concurrent schedules differ only in the rates of reinforcement they provide or in the operanda used to produce reinforcers (McSweeney, Weatherly, \& Roll, 1995). That is, the parameters and fit of the GML remain constant across the session, despite substantial within-session changes in absolute response rates. However, the parameters and fit do change systematically within sessions when the two components provide qualitatively different reinforcers, such as food and water (McSweeney, Swindell, \& Weatherly, 1996). As was argued earlier, this implies that the parameters and fit of the GML depend on the time in the session at which they are measured and differ for sessions of different length.

In the present experiments, the question of whether within-session changes in responding distort the interpretation of the GML when the components provide different simple schedules of reinforcement was examined. In the experiments, within-session changes in response rates and time spent responding during concurrent fixed interval (FI) variable interval (VI) schedules when rats (Experiment 1) and pigeons (Experiment 2) served as subjects were examined. The ratio of the programmed rates of reinforcement changed across conditions, so that the GML could be fit to the data. Two species of subjects were used in order to examine the generality of the results.

\section{EXPERIMENT 1}

\section{Method}

Subjects. The subjects were 5 experimentally naive male rats, bred from Sprague-Dawley stock. They were maintained at approximately $85 \%$ of their free-feeding weights by postsession feedings, given when all the subjects had completed their daily sessions. Weights were established immediately before the experiment, which began when the subjects were approximately 120 days old. The subjects were housed individually and were exposed to a 12:12-h light:dark cycle.

Apparatus. The apparatus was a two-lever experimental enclosure, measuring $20 \times 24.5 \times 24.5 \mathrm{~cm}$. A $5 \times 5.5 \mathrm{~cm}$ opening, which allowed access to reinforcers (45-mg Noyes pellets), was centered on the front panel, $0.5 \mathrm{~cm}$ above the floor. Two $4 \times 1.5 \mathrm{~cm}$ levers appeared $2.5 \mathrm{~cm}$ from this opening, one on each side. The levers were $5 \mathrm{~cm}$ above the floor and extended $1.5 \mathrm{~cm}$ into the enclosure. A 2-cm-diameter light was located $2.5 \mathrm{~cm}$ above each lever. A third 2-cm-diameter light was centered on the front panel, $4 \mathrm{~cm}$ from the ceiling. The houselight was another 2-cm-diameter light, located in the center of the ceiling. The apparatus was enclosed in a sound-attenuating chamber. An exhaust fan masked noises from outside. Experimental events were presented and data were recorded by MED Associates software run by an IBM-compatible 486 computer, located in another room.

Procedure. Each subject was placed in the apparatus until the left and right levers had each been pressed 100 times on a continuous reinforcement schedule. Then the experiment began. In the first condition, the subjects responded on a concurrent FI 60-sec VI 60$\mathrm{sec}$ schedule. Pressing the left lever produced reinforcers according to the FI schedule; pressing the right lever produced reinforcers according to the VI schedule. A reinforcer consisted of a 45-mg Noyes pellet. Reinforcers for the VI schedule were programmed by a 25 interval Fleshler and Hoffman (1962) series. A 3-sec changeover delay (COD), during which responses were not reinforced, followed all changes from one operandum to the other. The houselight and the lights above the left and right levers were illuminated throughout the 60 -min sessions. Sessions were conducted daily, five to six times per week.

When the subjects had responded on the concurrent FI 60-sec VI $60-\mathrm{sec}$ schedule for 30 sessions, they were exposed to the following schedules in the following order: concurrent FI 240-sec VI 15 sec, concurrent VI 120-sec FI 30-sec, concurrent VI 30-sec FI 120sec, and concurrent FI 15 -sec VI 240 -sec. The schedule presented on the left lever is listed first. Each schedule was studied for 30 sessions. These schedule values were selected because they provided the same rates of reinforcement as the schedules studied by McSweeney et al. (1995) and by McSweeney, Swindell, and Weatherly (1996), with which the present results will be compared. A final, concurrent VI 60-sec FI 60-sec schedule was planned, but problems with the computer delayed completion of this schedule. Because the subjects were old after the repair period and 1 subject died, the results of this final condition are not reported.

\section{Results and Discussion}

Figure 1 presents rates of responding (responses per minute) during successive 5-min intervals in the session for each component of each concurrent schedule. Response rates were averaged over the last five sessions for which each concurrent schedule was available and over all the rats. Each graph presents the results for a concurrent schedule. Circles represent responding on the FI components; triangles, responding on the VI components. Here, and throughout this paper, the value of the FI schedule is presented first in the labels of the graphs.

Figure 1 shows that rate of responding, averaged over the session, usually increased with increases in the programmed rates of reinforcement but declined at the highest rate of reinforcement for the FI components. The mean rates of responding during the FI components, averaged over all the subjects, were $2.1,13.1,21.7,44.8$, and 21.5 responses per minute, when results are presented from the leanest to the richest component. The mean rates of responding during the VI components were $2.5,12.2,11.7$, 25.6 , and 36.2 responses per minute for the schedules presented in the same order. Although rates of responding often increase with increases in rates of reinforcement (see, e.g., Catania \& Reynolds, 1968; Herrnstein, 1970), decreases in response rates at high programmed rates of reinforcement are frequently reported (e.g., Dougan \& McSweeney, 1985; McSweeney \& Melville, 1991) and are consistent with several theories (Baum, 1981; Staddon, 1979).

Figure 1 also suggests that rates of responding changed within sessions. Early-session increases in responding are visible in most graphs, followed by constant or decreasing late-session responding. Table 1 (top part) confirms this visual impression. It presents the results of one-way (5-min interval) repeated measures analyses of 


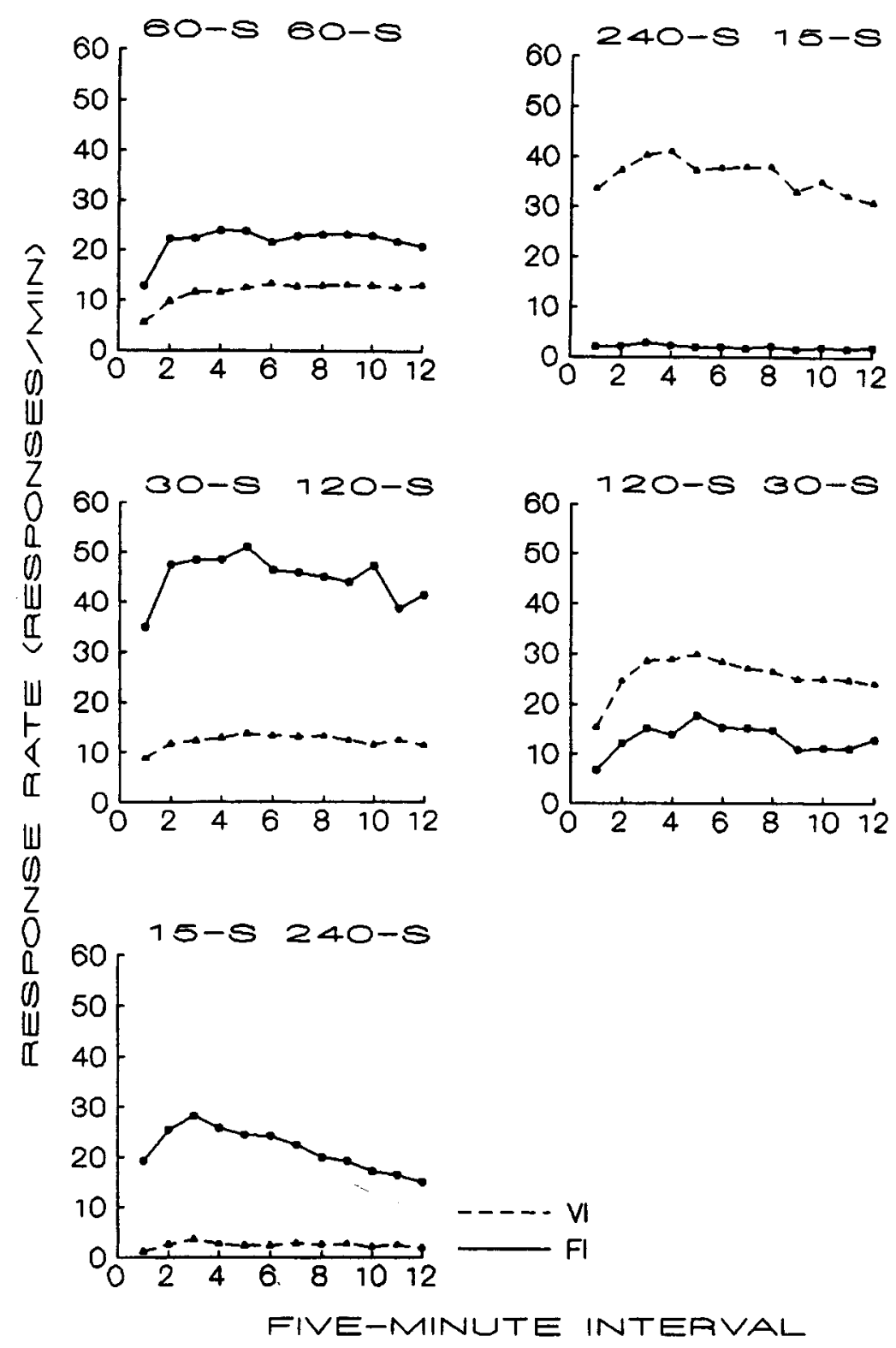

Figure 1. Rates of responding (responses per minute) during successive 5-min intervals in the session for the mean of all the rats responding on each component of each concurrent schedule in Experiment 1. Circles represent responding on the FI component; triangles represent responding on the VI component. The results were averaged over the last five sessions for which each schedule was available.

variance (ANOVAs) applied to rates of responding by individual subjects. Rate of responding changed significantly $(p<.05)$ within the session for all the components except the FI and VI 240 -sec. Past studies also reported that within-session changes in responding are smaller and may fail to reach statistical significance when schedules provide low rates of reinforcement (e.g., McSweeney, 1992; McSweeney, Roll, \& Cannon, 1994).

Figure 2 presents the time spent responding on the FI component (in seconds) during successive 5-min intervals in the session for each concurrent schedule. Time spent was calculated by a timer that started when the subject responded on the FI component and stopped when the subject switched to the VI component. Results are presented only for the FI component, because the time spent responding on the two components summed to the 300 total sec available for all 5-min intervals except the first. The time to the first response was not included in the time spent responding for either component in the first interval. Each graph presents the results for a different concurrent 
Table 1

Results of One-Way (5-Min Interval) Repeated Measures Analyses of Variance Applied to the Rate of Responding on the Fixed Interval (FI) and Variable Interval (VI) Components of Each Concurrent Schedule and the Time Spent Responding on the FI Component, for Each Concurrent Schedule

\begin{tabular}{|c|c|c|c|c|c|c|c|}
\hline \multirow[b]{2}{*}{ Schedule } & \multirow[b]{2}{*}{$d f$} & \multicolumn{2}{|c|}{ FI } & \multicolumn{2}{|c|}{ VI } & \multicolumn{2}{|c|}{ Time Spent } \\
\hline & & $F$ & $M S_{\mathrm{e}}$ & $F$ & $M S_{\mathrm{e}}$ & $F$ & $M S_{\mathrm{e}}$ \\
\hline \multicolumn{8}{|c|}{ Rats in Experiment 1} \\
\hline FI 60-sec VI 60-sec & 11,44 & $2.600^{*}$ & 16.996 & $8.391 \ddagger$ & 2.861 & 1.743 & 122.747 \\
\hline FI $240-\sec$ VI $15-\mathrm{sec}$ & 11,44 & 0.680 & 0.825 & $2.517^{*}$ & 20.770 & 1.154 & 30.224 \\
\hline FI 30 -sec VI 120 -sec & 11,44 & $3.131 \dagger$ & 32.894 & $2.714 \dagger$ & 3.177 & 1.778 & 220.298 \\
\hline FI $120-\sec$ VI $30-\sec$ & 11,44 & $3.772 \ddagger$ & 10.902 & $5.416 \ddagger$ & 13.091 & 1.601 & 116.972 \\
\hline FI 15-sec VI 240-sec & 11,44 & $9.516 \ddagger$ & 9.205 & $1.335^{\circ}$ & 1.199 & $5.464 \ddagger$ & 21.416 \\
\hline \multicolumn{8}{|c|}{ Pigeons in Experiment 2} \\
\hline FI 60-sec VI 60-sec & 11,33 & 1.577 & 22.911 & $2.854 \dagger$ & 16.261 & 1.047 & 368.242 \\
\hline FI 15-sec VI 240-sec & 11,33 & $3.195 \dagger$ & 57.531 & & & 0.457 & 803.198 \\
\hline FI $120-\sec$ VI $30-s e c$ & 11,33 & $5.177 \ddagger$ & 5.671 & 1.940 & 15.126 & 2.017 & 602.100 \\
\hline FI $30-\sec$ VI $120-$ sec & 11,33 & 1.382 & 54.810 & 0.669 & 5.145 & $2.465^{*}$ & 162.272 \\
\hline FI $240-\mathrm{sec}$ VI $15-\mathrm{sec}$ & 11,33 & 1.494 & 0.245 & $7.565 \ddagger$ & 11.443 & 0.807 & 433.976 \\
\hline FI $60-\mathrm{sec}$ VI $60-\mathrm{sec}$ & 11,33 & 1.431 & 10.797 & $4.048 \ddagger$ & 8.587 & 0.753 & 500.861 \\
\hline
\end{tabular}

${ }^{*} p<.05 .{ }^{\dagger} p<.01 .{ }^{\ddagger} p<.001$.

schedule. The results were averaged over all the subjects, responding during the final five sessions for which each concurrent schedule was available.

Figure 2 shows that time spent responding on the FI component (and, therefore, the VI component) changed little within sessions. One-way (5-min interval) repeated measures ANOVAs applied to time spent responding on the FI component appear in the top of Table 1. They show that the time spent responding on the FI component did not change significantly within sessions for any schedule except the concurrent FI 15-sec VI 240-sec. For that schedule, all of the change in the time spent responding occurred between the first and the second 5-min interval. Time spent on the FI component was constant over the rest of the session.

Figure 3 presents the parameters of the GML and the percentage of the variance accounted for by the GML, during successive 5-min intervals in the session. A linear least-squares procedure was used to fit the GML to the logarithms of the ratios of the appropriate variables (see Equation 1) for each subject. The presented results are the mean for all the subjects. The left graphs present the results when the GML was fit to the ratio of response rates (response matching). The right graphs present the results when the GML was fit to the ratio of the times spent responding (time matching). In all cases, results for the FI component were divided by those for the VI component. The GML was fit, using a log-linear procedure, to make the results comparable with those of past studies (e.g., McSweeney, Swindell, \& Weatherly, 1996).

The GML fit the data well. Except for one point, it always accounted for more than $90 \%$ of the variance in the data. As in other studies of concurrent VI FI schedule responding (Lobb \& Davison, 1975; Nevin, 1971; Trevett, Davison, \& Williams, 1972), the sensitivity parameters were less than 1 (undermatching). Consistent with the present results, Lobb and Davison (1975) reported larger sen- sitivity parameters for time than for response matching. However, on the basis of an analysis of the results of three studies (Lobb \& Davison, 1975; Nevin, 1971; Trevett et al., 1972), they also argued that sensitivity for concurrent FI VI schedules is approximately .63 for response and .69 for time matching. The present sensitivities are somewhat larger than these values (mean $=.733$ for response matching; mean $=.836$ for time matching). This difference may have been produced by many differences between the studies. However, one difference can probably be ruled out. The difference in results was probably not produced by the species of subjects used. The parameters reported in Experiment 2 were also larger than those reported by Lobb and Davison, even when the same species (pigeons) served as subjects in both experiments. Finally, the subjects were biased toward the VI schedule (bias < 1.0) for time matching, as reported by Lobb and Davison and Trevett et al., but they were biased toward the FI schedule (bias $>1.0$ ) for response matching. Differences in the species used in the studies may have contributed to this difference. Experiment 2, which used pigeons as subjects, reported a bias toward the VI schedule.

The parameters and fit of the GML usually changed little and inconsistently across the session. One-way (5-min interval) repeated measures ANOVAs applied to the parameters and fits showed that these variables did not change significantly within sessions for either response [sensitivity, $F(11,44)=0.764, M S_{\mathrm{e}}=0.015$; bias, $F(11,44)=$ $1.489, M S_{\mathrm{e}}=0.039$; percentage, $F(11,44)=1.782, M S_{\mathrm{e}}=$ 18.313] or time [sensitivity, $F(11,44)=1.369, M S_{\mathrm{e}}=$ 0.006 ; bias, $F(11,44)=1.588, M S_{\mathrm{e}}=0.012$; percentage, $\left.F(11,44)=1.027, M S_{\mathrm{e}}=10.751\right]$ matching.

McSweeney, Weatherly, and Swindell (1996) reported that the within-session change in the sum of instrumental responding was indistinguishable from the withinsession change in the number of changeovers when subjects responded on a concurrent VI VI schedule. This 


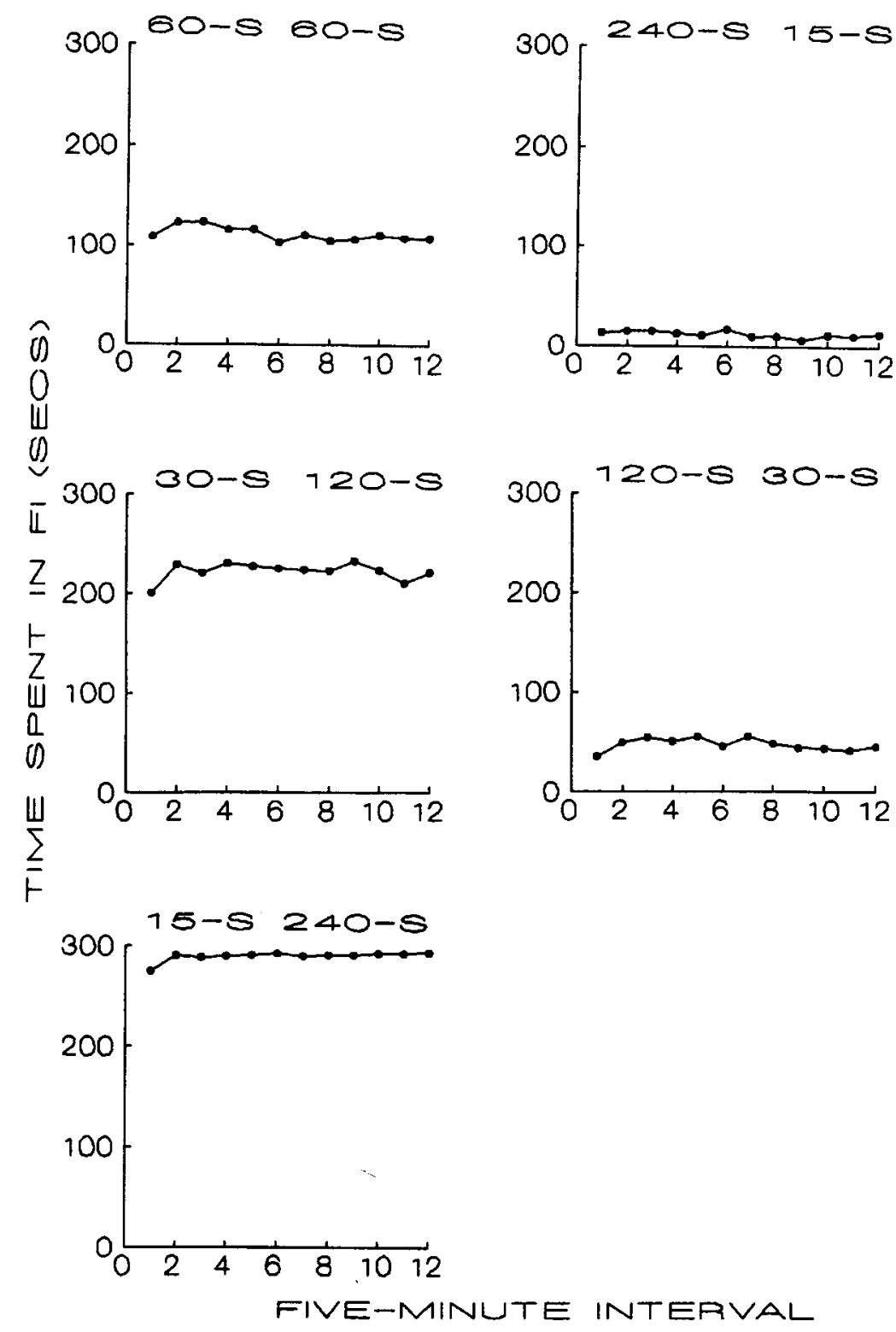

Figure 2. The time spent responding (in seconds) on the fixed interval component during successive 5-min intervals for the mean of all the rats responding on each concurrent schedule in Experiment 1 . The results were averaged over the last five sessions for which each schedule was available.

similarity occurred except at very high rates of reinforcement (i.e., a concurrent VI 11.25-sec VI 22.5-sec schedule). Figure 4 compares the number of changeovers with the sum of instrumental responses for the present concurrent FI VI schedules. Percentages were calculated so that differences in the absolute rates of responding and changing over would not obscure similarities in the withinsession patterns of responding. Percentages were calculated by dividing the number of changeovers (or sum of responding) during a 5-min interval by the total number of changeovers (or sum of responses) during the session and multiplying by 100 .

Figure 4 suggests that within-session patterns differed for the number of changeovers and the sum of instrumental responses, when subjects responded on the present concurrent FI VI schedules. The interaction terms of two-way (behavior $\times 5$-min interval) repeated measures ANOVAs confirmed this conclusion. They were statistically significant for each schedule [concurrent FI 60-sec VI 60sec, $F(11,44)=5.611, M S_{\mathrm{e}}=8.685$; concurrent FI 240- 
RESPONSES
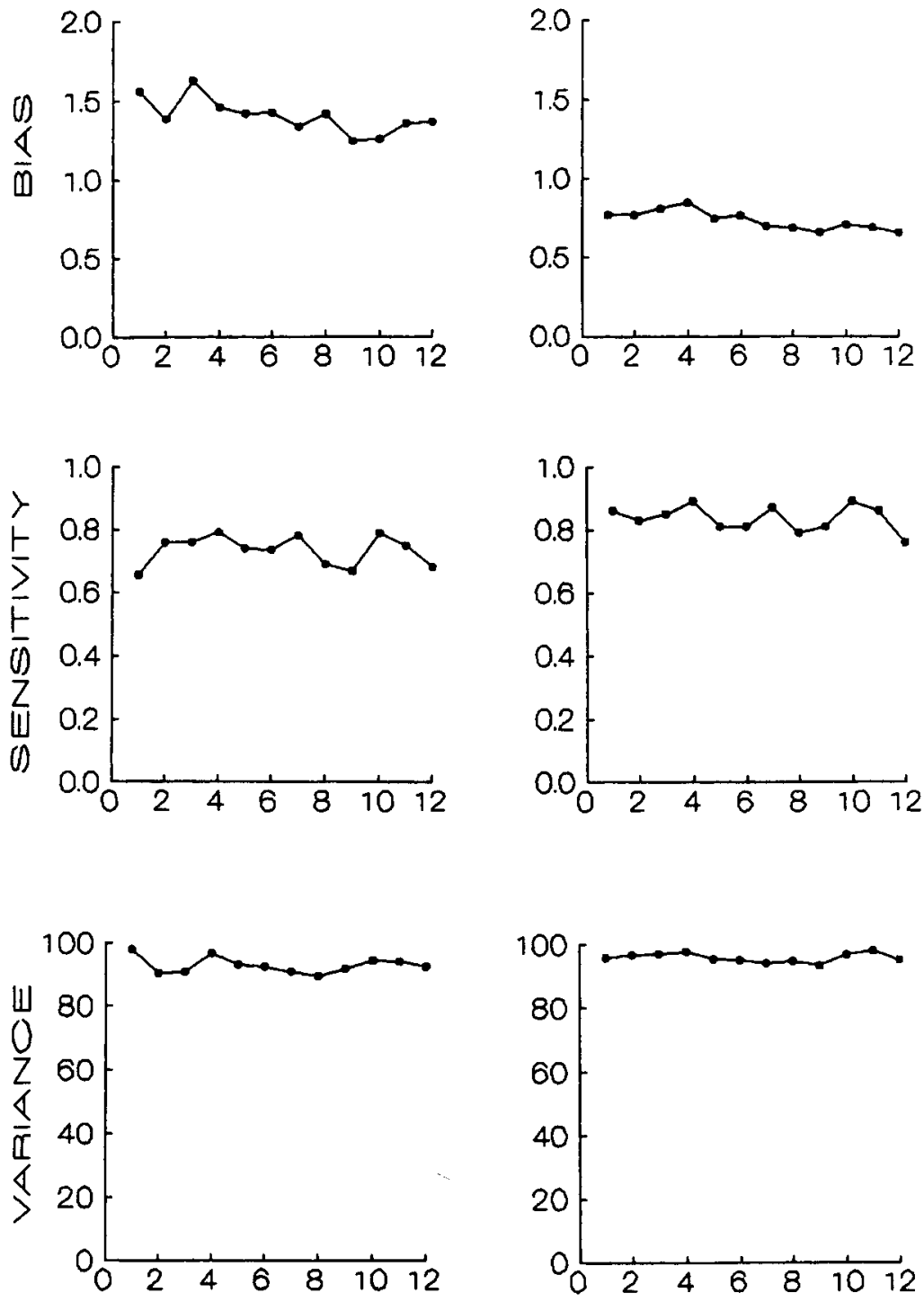

FIVE-MINUTE INTERVAL

Figure 3. The bias (top graphs) and sensitivity (middle graphs) parameters of the generalized matching law, as well as the percentage of the variance accounted for (bottom graphs), when the generalized matching law was applied to the ratios of the rates of responding (left graphs) and to the ratios of the time spent responding (right graphs) in Experiment 1. Parameters were calculated from the data in successive 5min intervals and were averaged over all the rats.

sec VI 15-sec, $F(11,44)=2.848, M S_{\mathrm{e}}=9.948$; concurrent FI 30-sec VI 120-sec, $F(11,44)=3.636, M S_{\mathrm{e}}=17.612$; concurrent FI 120-sec VI $30-\mathrm{sec}, F(11,44)=5.939, M S_{\mathrm{e}}=$ 13.487; concurrent FI 15-sec VI 240-sec, $F(11,44)=$ $\left.10.045, M S_{\mathrm{e}}=4.826\right]$.

\section{EXPERIMENT 2}

\section{Method}

Subjects. The subjects were 4 experimentally experienced pigeons, maintained at approximately $85 \%$ of their free-feeding body weights by postsession feedings, delivered when all the subjects had completed the daily session. The subjects were housed individually and were exposed to a 12:12-h light:dark cycle.

Apparatus. The apparatus was a three-key experimental enclosure, measuring $30 \times 36 \times 27 \mathrm{~cm}$. Three 2.5 -cm-diameter keys were positioned $21.5 \mathrm{~cm}$ above the floor and $7.5 \mathrm{~cm}$ apart. The left key was $7 \mathrm{~cm}$ from the left wall; the right key, $7.5 \mathrm{~cm}$ from the right wall. A force of approximately $0.25 \mathrm{~N}$ operated each key. A $4.5 \times$ $5 \mathrm{~cm}$ opening allowed access to a food magazine. It was $7.5 \mathrm{~cm}$ above the floor and $15 \mathrm{~cm}$ from the right wall. A 4-cm-diameter houselight was located $1.5 \mathrm{~cm}$ from the ceiling and $0.5 \mathrm{~cm}$ from the right wall. The experimental panel was housed in a sound-attenuating 


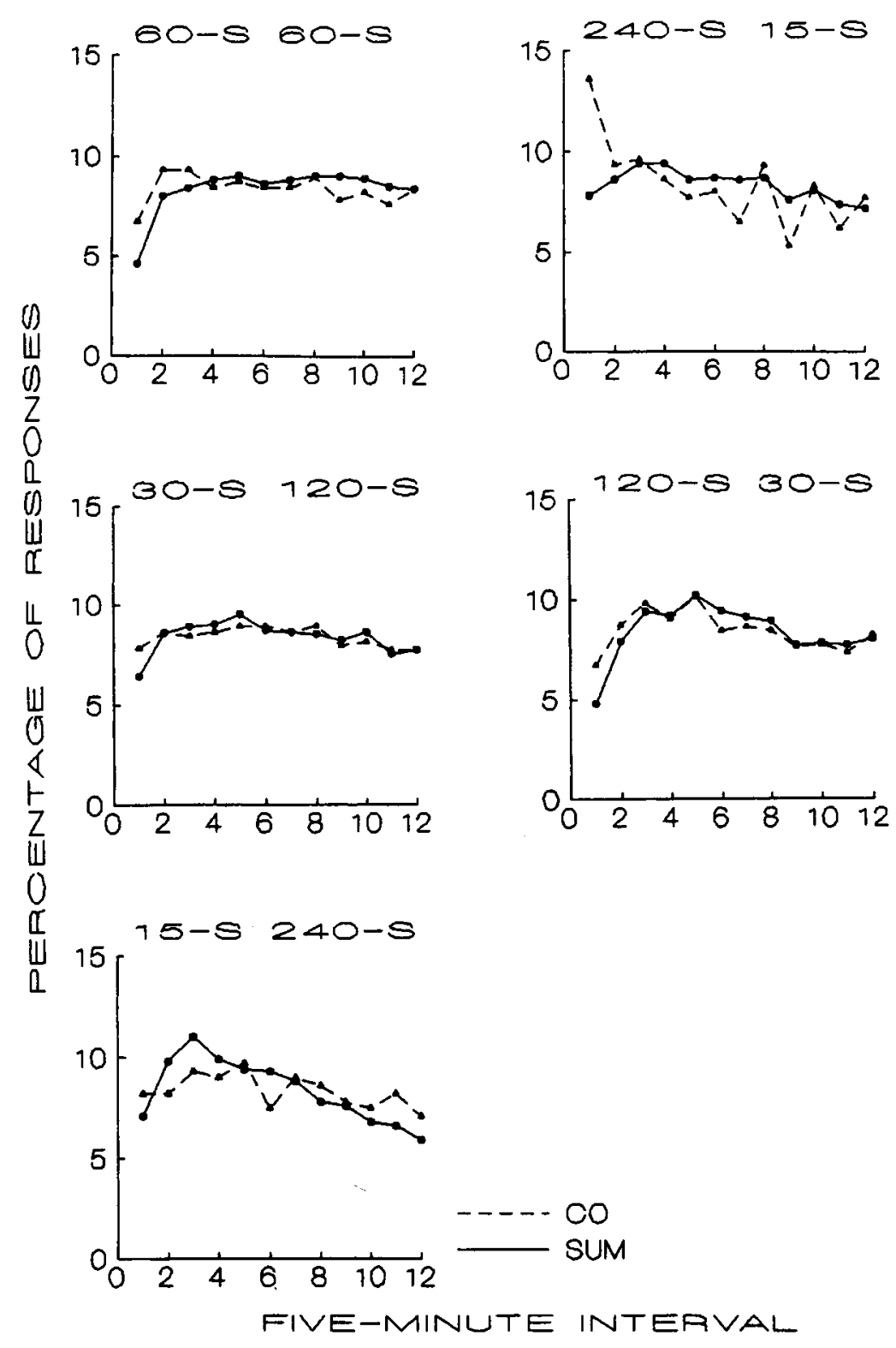

Figure 4. Percentage of total-session changeovers (dashed line) and percentage of total-session responses (solid line) during successive 5-min intervals in the session in Experiment 1. Each graph presents percentages calculated on the response rates for the mean of all subjects responding on a concurrent schedule.

chamber. A ventilating fan masked noises from outside the chamber. Experimental events were programmed and data were recorded by MED Associates software run by an IBM-compatible $486 \mathrm{com}$ puter, located in another room.

Procedure. The subjects had pecked keys in previous experiments. Therefore, they were placed directly on the following schedules, presented in the following order: concurrent FI 60-sec VI 60sec, concurrent VI 240-sec FI 15-sec, concurrent FI 120-sec VI 30-sec, concurrent FI 30-sec VI 120-sec, concurrent VI 15-sec FI 240-sec, and concurrent VI 60-sec FI 60-sec. The component listed first was presented on the left key. The left and right keys were il- luminated with white light, except when a reinforcer (5-sec access to mixed grain) was presented. Reinforcement time was excluded from the calculation of session length. All the other procedural details were similar to those for the rats.

\section{Results and Discussion}

Figure 5 presents rates of responding (responses per minute) during successive 5-min intervals in the session for the mean of all the pigeons responding on each concurrent schedule. The results were calculated and pre- 


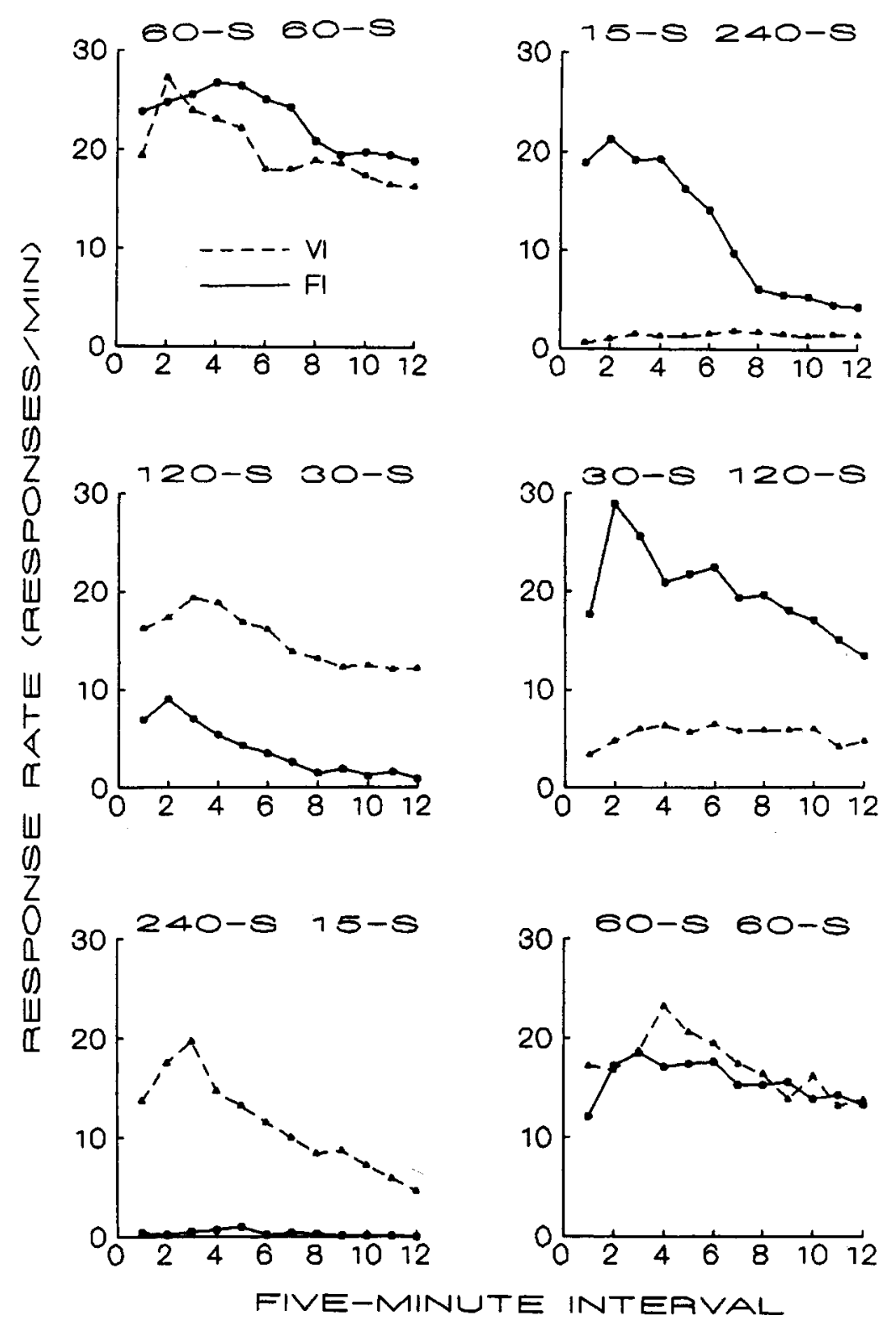

Figure 5. Rates of responding (responses per minute) during successive 5-min intervals in the session for the mean of all the pigeons responding on each component of each concurrent schedule in Experiment 2. Circles represent responding on the fixed interval component; triangles represent responding on the variable interval component. The results were averaged over the last five sessions for which each schedule was available.

sented as in Figure 1. The time for which reinforcement was available was excluded from session time when calculating response rates.

Figure 5 shows that rates of responding, averaged over the session, increased with increases in the rates of reinforcement provided by the component up to a point and then decreased with further increases. The mean rates of responding during the FI components were $0.3,3.8,19.3$, 20 , and 12 , responses per minute, when results were presented from the leanest to the richest components. The mean rates of responding during the VI components were $1.4,5.4,18.6,15$, and 11.3 responses per minute from the leanest to the richest components. As was argued earlier, rate of responding often increases with increases in rate of reinforcement, but may decrease at high reinforcer rates.

Figure 5 shows that response rates often changed within sessions. With a few exceptions, response rate usually increased and then decreased. However, these withinsession changes in response rates were not always statistically significant. The results of one-way (5-min inter- 

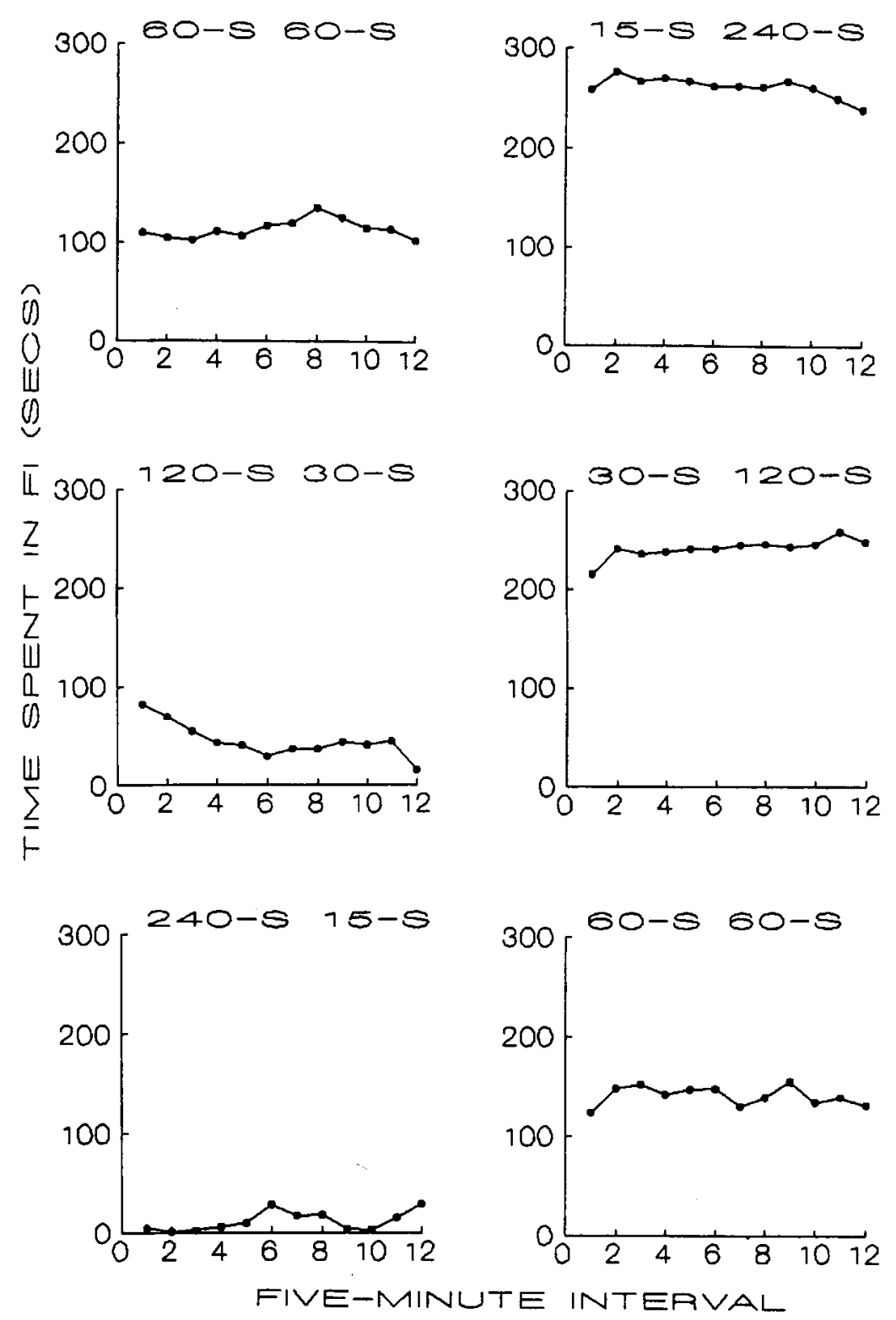

Figure 6. The time spent responding on the fixed interval component during successive 5-min intervals for the mean of all the pigeons responding on each concurrent schedule in Experiment 2. The results were averaged over the last five sessions for which each schedule was available.

val) repeated measures ANOVAs, applied to rates of responding during each component of each concurrent schedule, appear in the bottom of Table 1 . An ANOVA was not calculated for the VI 240-sec component, because several subjects responded little during that component. Table 1 shows that ANOVAs were statistically significant approximately half of the time. The ANOVA was also close to significant for the VI 30-sec component of the concurrent FI 120-sec VI 30-sec schedule $(p<.070)$. As in Experiment 1 and in past studies (e.g., McSweeney, 1992; McSweeney, Roll, \& Cannon, 1994), within-session changes in responding were more likely to be significant when the components provided higher, rather than lower, rates of reinforcement.

Figure 6 presents time spent responding on the FI component during successive 5-min intervals for each concurrent schedule. The results were calculated and presented as were those for the rats. Figure 6 shows that time spent responding on the FI component was usually relatively constant within sessions. The results of one-way (5-min interval) repeated measures ANOVAs, applied to the time spent responding on the FI schedule, appear in the bottom of Table 1 . They were significant only for the concurrent FI 30-sec VI 120-sec schedule. However, the 

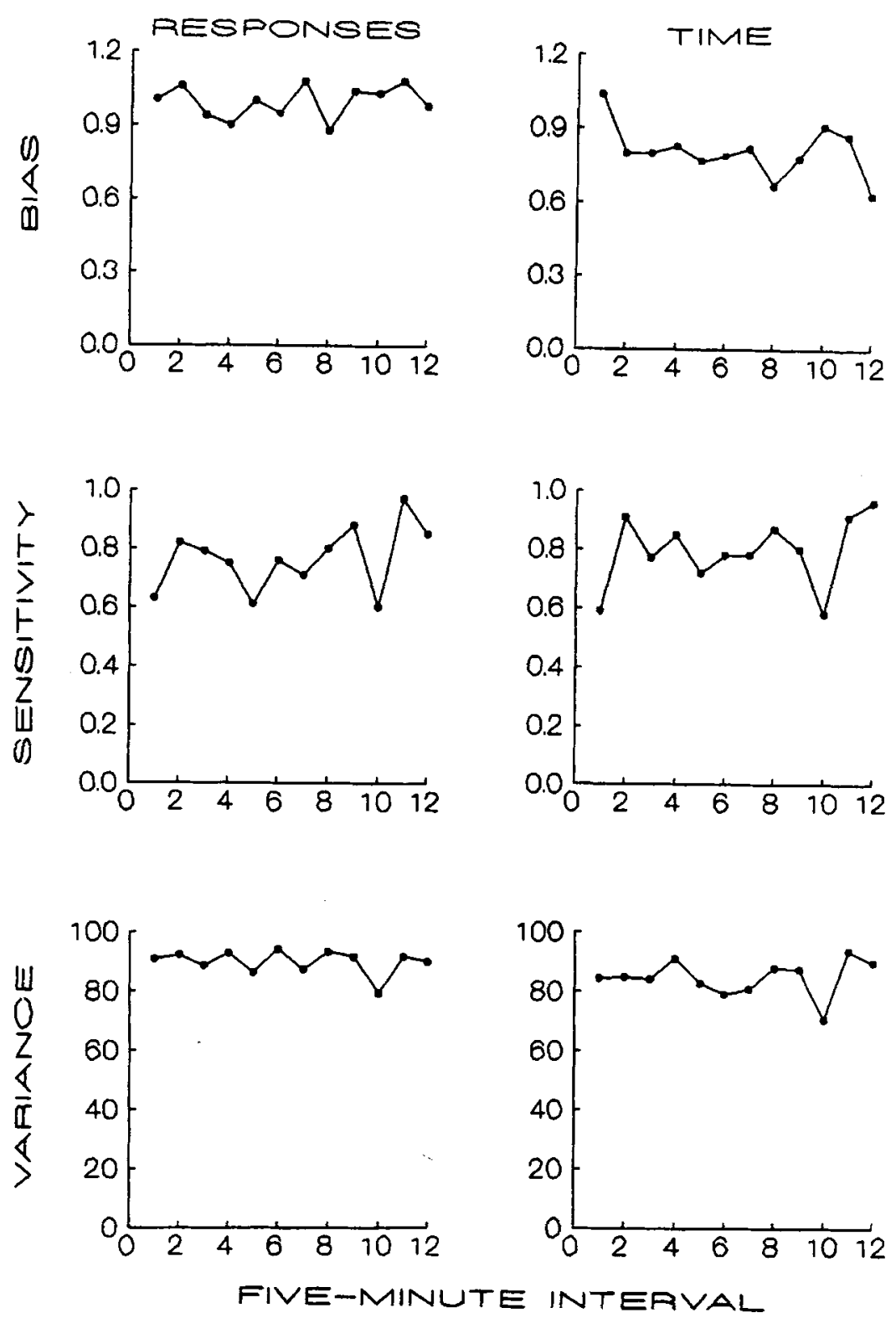

Figure 7. The bias (top graphs) and sensitivity (middle graphs) parameters of the generalized matching law, as well as the percentage of the variance accounted for (bottom graphs), when the generalized matching law was applied to the ratios of the rates of responding (left graphs) and to the ratios of the time spent responding (right graphs) in Experiment 2. Parameters were calculated from the data in successive 5-min intervals and were averaged over all the pigeons.

ANOVA also approached significance $(p<.059)$ for the concurrent FI 120-sec VI 30-sec schedule.

Figure 7 presents the parameters and fit of the GML during successive 5 -min intervals in the session. The results were analyzed and presented as in Figure 3 . The results are those for the means of only 3 subjects. One subject often stopped responding at the end of the session, making it difficult to fit the GML to the data for this subject.

There is a great deal of variance from interval to interval in Figure 7. The fit of the GML was not as good as that for the rats in Experiment 1. The percentage of the variance accounted for by Equation 1 was usually greater than $80 \%$ for response matching $(M=89.7 \%)$ and always greater than $70 \%$ for time matching $(M=84.7 \%)$. Sensitivity parameters usually fell in the range of $.60-1$ for both response and time matching. Again, these sensitivity parameters are somewhat larger than those reported in past studies. As was reported earlier, Lobb and Davison (1975) concluded that the sensitivity parameters for concurrent FI VI schedules were approximately .63 for 

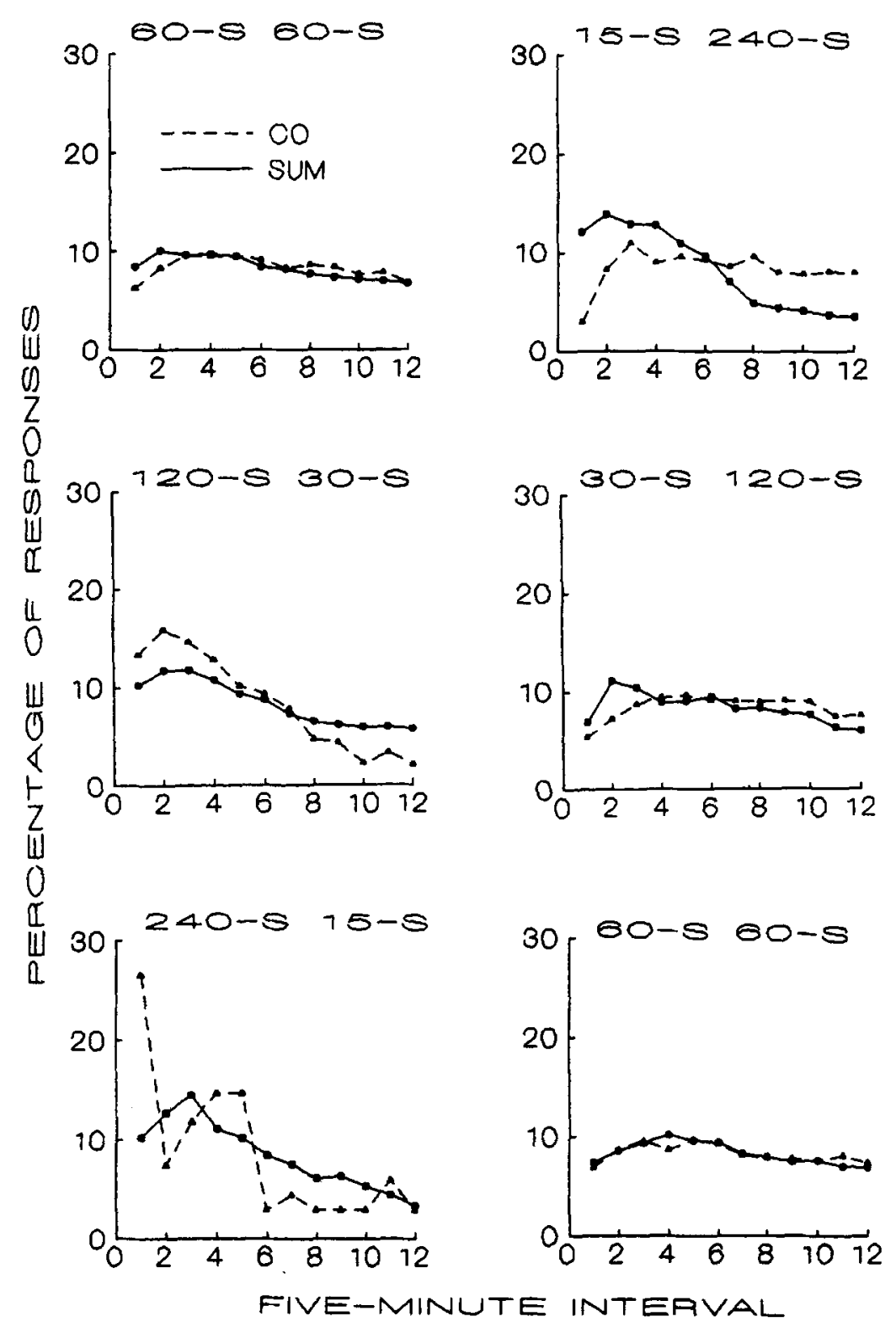

Figure 8. Percentage of total-session changeovers (dashed line) and total-session responses (solid line) during successive 5-min intervals in the session in Experiment 2. Each graph presents percentages calculated on the response rates for the mean of all the subjects responding on a concurrent schedule.

response matching and .69 for time matching. The comparable means in the present experiment were .76 and .79 . Consistent with the results reported in Experiment 1 and by Lobb and Davison, sensitivities were somewhat greater for time than for response matching. But this difference was small in the present experiment.

Figure 7 shows little bias for response matching. That is, the mean bias parameter of 0.996 was close to 1 . Except for the first 5 -min interval, time matching was biased toward the VI schedule (bias $<1, M=0.809$ ). Trevett et al. (1972) and Lobb and Davison (1975) also reported a consistent bias toward the VI schedule when pigeons responded on concurrent FI VI schedules. In contrast, Nevin (1971) reported that the direction of bias differed for different subjects. However, his data are hard to interpret, because the FI schedule always appeared on the same key. Therefore, bias might represent a key preference rather than a schedule preference.

Figure 7 shows that the parameters and fit of the GML did not usually change systematically within sessions. One-way (5-min interval) repeated measures ANOVAs, applied to the parameters and fits for individual subjects, showed that only the sensitivity parameter for response matching changed significantly within the session 
$\left[F(11,22)=2.485, M S_{\mathrm{e}}=0.016\right]$. Figure 7 shows that this change was unsystematic. The other parameters and fits did not change significantly for either response [bias, $F(11,22)=0.281, M S_{\mathrm{e}}=0.049$; percentage, $F(11,22)=$ $0.799, M S_{\mathrm{e}}=63.248$ ] or time [bias, $F(11,22)=1.061$, $M S_{\mathrm{e}}=0.030$; sensitivity, $F(11,22)=1.360, M S_{\mathrm{e}}=0.032$; percentage, $\left.F(11,22)=0.809, M S_{\mathrm{e}}=139.999\right]$ matching. The conclusion would not have been changed if the results had been averaged over all 4 subjects responding during the first eight 5-min intervals of the session in which all the subjects responded. The parameters and fit of the GML did not change significantly within the session for either response [bias, $F(7,21)=1.084, M S_{\mathrm{e}}=0.087$; sensitivity, $F(7,21)=0.251, M S_{\mathrm{e}}=0.037$; percentage, $F(7,21)=0.978$, $\left.M S_{\mathrm{e}}=97.422\right]$ or time [bias, $F(7,21)=2.179, M S_{\mathrm{e}}=0.029$; sensitivity, $F(7,21)=0.199, M S_{\mathrm{e}}=0.073$; percentage, $\left.F(7,21)=0.731, M S_{\mathrm{e}}=282.869\right]$ matching.

Figure 8 compares within-session changes in the number of changeovers with within-session changes in the sum of instrumental responding. The results were calculated and presented as in Figure 4. Again, the within-session patterns appear to differ for the two measures. The interaction terms of two-way (behavioral measure $\times 5$-min interval) repeated measures ANOVAs showed that the patterns differed significantly for three of the concurrent schedules [concurrent FI 15-sec VI 240-sec, $F(11,33)=$ 2.846, $M S_{\mathrm{e}}=31.711$; concurrent FI 240-sec VI 15-sec, $F(11,33)=7.020, M S_{\mathrm{e}}=5.910$; second concurrent FI 60sec VI 60-sec, $F(11,33)=4.033, M S_{\mathrm{e}}=6.932 \mathrm{]}$. The test was marginally significantly different $(p<.066)$ for a fourth schedule [concurrent FI 120-sec VI 30-sec, $\left.F(11,33)=1.965, M S_{\mathrm{e}}=11.433\right]$. The tests failed to reach significance for only two schedules [first concurrent FI 60-sec VI 60-sec, $F(11,33)=1.462, M S_{\mathrm{e}}=34.077$; concurrent FI $30-\mathrm{sec}$ VI $120-\mathrm{sec}, F(11,33)=1.588, M S_{\mathrm{e}}=$ 24.772].

\section{GENERAL DISCUSSION}

Rate of responding often changed within sessions for rats (Experiment 1) and pigeons (Experiment 2). This extends the generality of within-session changes in responding to concurrent FI VI schedules. As in past studies (e.g., McSweeney, 1992; McSweeney, Roll, \& Cannon, 1994), the within-session changes in responding were more likely to be statistically significant when the components provided higher, rather than lower, rates of reinforcement.

Time spent responding on a component schedule rarely changed significantly within sessions for either rats or pigeons (Figures 2 and 6). In contrast, McSweeney, Swindell, and Weatherly (1996) reported systematic within-session changes in the time spent responding, when the subjects responded on concurrent VI VI schedules that provided different reinforcers (e.g., food and water) in the two components. The conditions under which time spent responding changes systematically within ses- sions require further study. Too few data exist to speculate about these conditions.

The parameters and fit of the GML did not change systematically within sessions (Figures 3 and 7). The only exception was the small increase in the sensitivity parameters for pigeons, when response matching was examined. Because the parameters and fit were relatively constant within sessions, the description of the data provided by the GML did not differ at different times within the session and should not differ for sessions of different lengths. Therefore, within-session changes in responding do not create problems for assessing the validity of the GML when subjects respond on concurrent FI VI schedules. However, within-session changes in responding should be studied during concurrent schedules that provide other simple schedules, before it is assumed that withinsession changes do not create problems for any type of concurrent schedule with different simple schedules in the components. Substantially different results might occur if the component schedules differed more than they did here (e.g., a ratio vs. an interval schedule).

It might be argued that the parameters and fit of the GML did not change systematically within sessions in the present study because the subjects actually experienced the concurrent FI VI schedules as concurrent VI VI schedules. The parameters and fit of the GML do not change within sessions when subjects respond on concurrent VI VI schedules (McSweeney et al., 1995; McSweeney, Weatherly, \& Swindell, 1996).

It seems unlikely that the subjects would fail to discriminate between concurrent FI VI and concurrent VI VI schedules. The obtained distribution of interreinforcement times should differ substantially for these schedules. In particular, the distribution should lack interreinforcer intervals shorter than the programmed FI, when subjects respond on FI schedules. In contrast, reinforcers can be obtained even at very short interreinforcer intervals on VI schedules.

Behavior on the present concurrent FI VI schedules also differed from that reported on concurrent VI VI schedules. As was argued, McSweeney, Weatherly, and Swindell (1996) showed that the within-session change in the number of changeovers was indistinguishable from the within-session change in the sum of the rates of instrumental responding when subjects responded on concurrent VI VI schedules, except at very high rates of reinforcement (i.e., a concurrent VI 11.25-sec VI 22.5-sec schedule). The within-session changes for these two behavioral measures usually differed for the present concurrent FI VI schedules (Figures 4 and 8 ). The reason for this difference in performance is not known. The similarity between instrumental responses and changeovers suggests that responding and changeovers are regulated by the same mechanism on concurrent VI VI schedules. However, the differences between those behaviors on concurrent FI VI schedules suggests that responding and changing over are regulated differently on that schedule. 
Finding that the parameters and fit of the GML do not change within sessions is consistent with the idea that within-session changes in response rates are produced by changes in a multiplier that is the same for both components of the concurrent schedule. Such multipliers would cancel out when ratios of response rates were calculated to fit the GML. The idea of a constant multiplier is in turn consistent with McSweeney, Weatherly, and Swindell's (1996) conclusion that within-session patterns of responding during both components of a concurrent schedule are governed by approximately the sum of the reinforcers obtained from the two components, at least when subjects respond on concurrent schedules that provide qualitatively similar reinforcers in the two components. The sum of reinforcers would be similar for both components, yielding similar within-session patterns of responding. Similar within-session patterns would cancel out when ratios of response rates were calculated.

To date, within-session changes in response rates do not create problems for interpreting the GML, as long as the components provide the same type of reinforcer. This conclusion holds regardless of whether those reinforcers are provided at similar (McSweeney, Weatherly, \& Swindell, 1996) or different (McSweeney et al., 1995) rates, by similar (McSweeney, Weatherly, \& Swindell, 1996) or different (McSweeney et al., 1995) operanda, and by similar (e.g., McSweeney, Weatherly, \& Swindell, 1996) or different (Experiments 1 and 2) simple schedules. In contrast, within-session patterns may differ for the two components when the components provide qualitatively different reinforcers (McSweeney, Swindell, \& Weatherly, 1996).

The present results may help to explain why the GML provides a good description of responding. Systematic within-session changes in responding create problems for theories that predict the absolute rate at which subjects respond, averaged over the session (e.g., Herrnstein, 1970). Within-session changes in response rates imply that absolute response rates will differ, depending on the time in the session at which responding is measured and on the length of the session over which responding is averaged. Because significant within-session changes in responding have been reported for a wide variety of schedules, including simple (e.g., McSweeney, Roll, \& Weatherly, 1994), multiple (e.g., McSweeney, 1992), and concurrent (e.g., McSweeney et al., 1995), within-session changes create problems for interpreting absolute response rates during a wide variety of procedures.

In contrast, within-session changes create few problems for theories that predict the ratio of the rates of responding (e.g., the GML). To date, within-session changes in responding have been similar for the components of the concurrent schedule, unless those components provide qualitatively different reinforcers (McSweeney, Swindell,
\& Weatherly, 1996). Because the patterns are similar for the two components, within-session changes in responding cancel out when response ratios are taken. As a result, the adequacy of ratio theories as descriptions of responding do not differ at different times in the session or during sessions of different lengths.

\section{REFERENCES}

BAUM, W. M. (1974). On two types of deviation from the matching law: Bias and undermatching. Journal of the Experimental Analysis of Behavior, 22, 231-242.

BAUM, W. M. (1981). Optimization and the matching law as accounts of instrumental behavior. Journal of the Experimental Analysis of Behavior, 36, 387-403.

Catania, A. C., \& Reynolds, G. S. (1968). A quantitative analysis of the responding maintained by interval schedules of reinforcement. Journal of the Experimental Analysis of Behavior, 11, 327-383.

Dougan, J. D., \& MCSwEENEY, F. K. (1985). Variations in Herrnstein's $r_{0}$ as a function of alternative reinforcement rate. Journal of the Experimental Analysis of Behavior, 43, 215-223.

FLESHLER, M., \& HofFMAN, H. S. (1962). A progression for generating variable-interval schedules. Journal of the Experimental Analysis of Behavior, 5, 529-530.

HERRNSTEIN, R. J. (1970). On the law of effect. Journal of the Experimental Analysis of Behavior, 13, 243-266.

LOBB, B., \& DAVISON, M. C. (1975). Performance in concurrent interval schedules: A systematic replication. Journal of the Experimental Analysis of Behavior, 24, 191-197.

MCSWEENEY, F. K. (1992). Rate of reinforcement and session duration as determinants of within-session patterns of responding. Animal Learning \& Behavior, 20, 160-169.

McSweeney, F. K., \& Melville, C. L. (1991). Behavioral contrast as a function of component duration for leverpressing using a withinsession procedure. Animal Learning \& Behavior, 19, 71-80.

MCSweeney, F. K., Roll, J. M., \& Cannon, C. B. (1994). The generality of within-session patterns of responding: Rate of reinforcement and session length. Animal Learning \& Behavior, 22, 252-266.

MCSWEENEY, F. K., Roll, J. M., \& WeatherLy, J. N. (1994). Withinsession changes in responding during several simple schedules. Journal of the Experimental Analysis of Behavior, 62, 109-132.

McSWeEney, F. K., SWINdell, S., \& Weatherly, J. N. (1996). Withinsession changes in responding during concurrent schedules with different reinforcers in the components. Journal of the Experimental Analysis of Behavior, 66, 369-390.

McSWeeney, F. K., WeatherLy, J. N., \& Roll, J. M. (1995). Withinsession changes in responding during concurrent schedules that employ two different operanda. Animal Learning \& Behavior, 23, 237 244.

MCSWEeney, F. K., WEATHerly, J. N., \& SWINDELl, S. (1996). Withinsession changes in responding during concurrent variable-interval schedules. Journal of the Experimental Analysis of Behavior, 66, 7595.

NEvin, J. A. (1971). Rates and patterns of responding with concurrent fixed-interval and variable-interval reinforcement. Journal of the Experimental Analysis of Behavior, 16, 241-247.

STADDON, J. E. R. (1979). Operant behavior as adaptation to constraint Journal of Experimental Psychology: General, 108, 48-67.

Trevett, A. J., Davison, M. C., \& Williams, R. J. (1972). Performance in concurrent interval schedules. Journal of the Experimental Analysis of Behavior, 17, 369-374.

(Manuscript received August 31, 1998; revision accepted for publication December 8, 1998.) 